\title{
EXPERIMENTAL REFERRED PAIN FROM THE GASTRO-INTESTINAL TRACT. PART II. STOMACH, DUODENUM AND COLON
}

\author{
By A. L. BLOOMFIELD and W. S. POLLAND \\ (From the Department of Medicine, Stanford University School of Medicine, \\ San Francisco)
}

(Received for publication March 30, 1931)

INTRODUCTION

In the preceding paper of this series (3) observations on the pain resulting from inflation of the esophagus by small balloons were described. The general methods and purposes of the investigation were also outlined. The present communication deals with similar studies of referred sensation from the stomach, duodenum and colon.

\section{STOMACH}

Methods and material. A large balloon of thin rubber, so shaped that on inflation it assumed the general shape of the stomach, was constructed about the distal part of a mercury weighted stomach tube. The tube was passed into the stomach and then inflated by means of a large luer syringe fitted with a valve so that the amount of air introduced could be measured. The stomach tube was also connected with a $U$ mercury manometer to measure pressure (see Fig. 1).

Sixteen subjects were studied. They were hospital patients and included people with and without stomach disorders. The following points were analyzed: (1) the amount of inflation necessary to produce pain, (2) the location of the pain, (3) the character of the pain, (4) the relation of pain to spontaneous sensations and to that produced by inflation of esophagus and duodenum and (5) the mechanism of the induced sensations. The results are summarized in Table I.

The character of the sensations. The main features of the referred sensation from gastric inflation was its indefinite quality. It was almost impossible to get exact descriptions from the subjects, but on the 
whole the sensations resembled those encountered ordinarily from overloading the stomach-feelings of fullness, tightness or pressure with more or less of a painful element superimposed. In several cases there were reflex attempts to rid the stomach of the large foreign body by means of belching, or violent nausea and retching supervened. It was

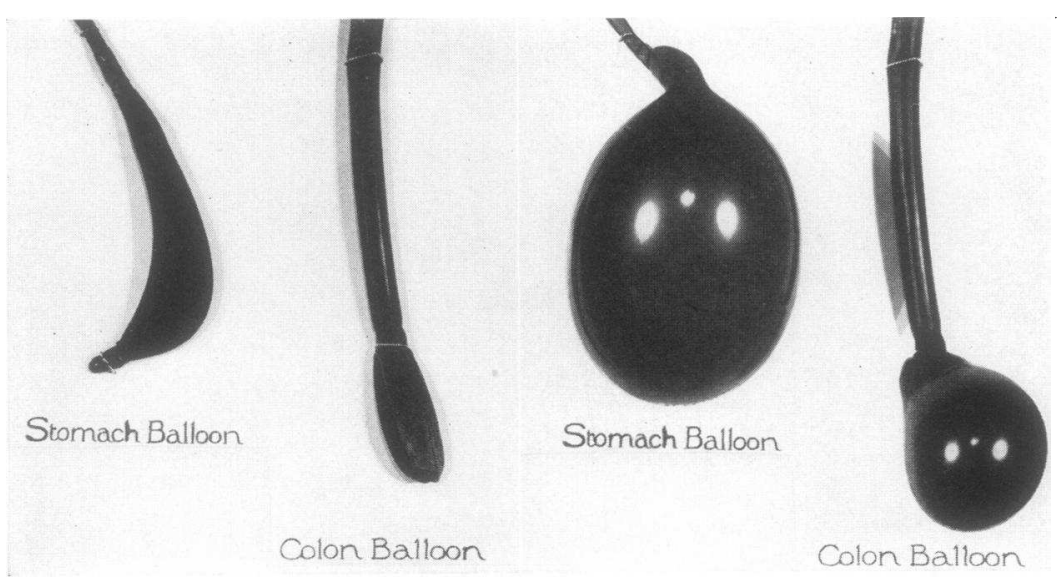

Fig. 1. Stomach and Colon Balloons-Inflated and Collapsed

of interest to observe how violently sick the subject could be as the result of a purely mechanical stimulus. When more than $600-700 \mathrm{cc}$. of air were introduced the stomach outline began to stand out as a visible fullness; in no case was there visible peristalsis. Case 14 is of interest insofar as no definite sensation resulted from distension with $1500 \mathrm{cc}$. of air. In other cases discomfort resulted (see Table I) from 200 to 400 or $500 \mathrm{cc}$. Except in Case 14, who seemed to be generally hyposusceptible to pain, no relation was found between the threshold stimulus and the patient's general nervous make-up or the presence of disease of the stomach. Cases 12 and 15, for example, with peptic ulcer responded very slightly to inflation.

When inflation was started the pressure in the bag rose rapidly to about $40 \mathrm{~mm}$. $\mathrm{Hg}$. and then usually remained at about this level. Apparently the stomach dilated readily on further introduction of air without exerting much increased pressure.

The location of the induced sensations. Inflation of the stomach gave sensations which were much less sharply localized than those from the 
A. L. BLOOMFIELD AND W. S. POLLAND

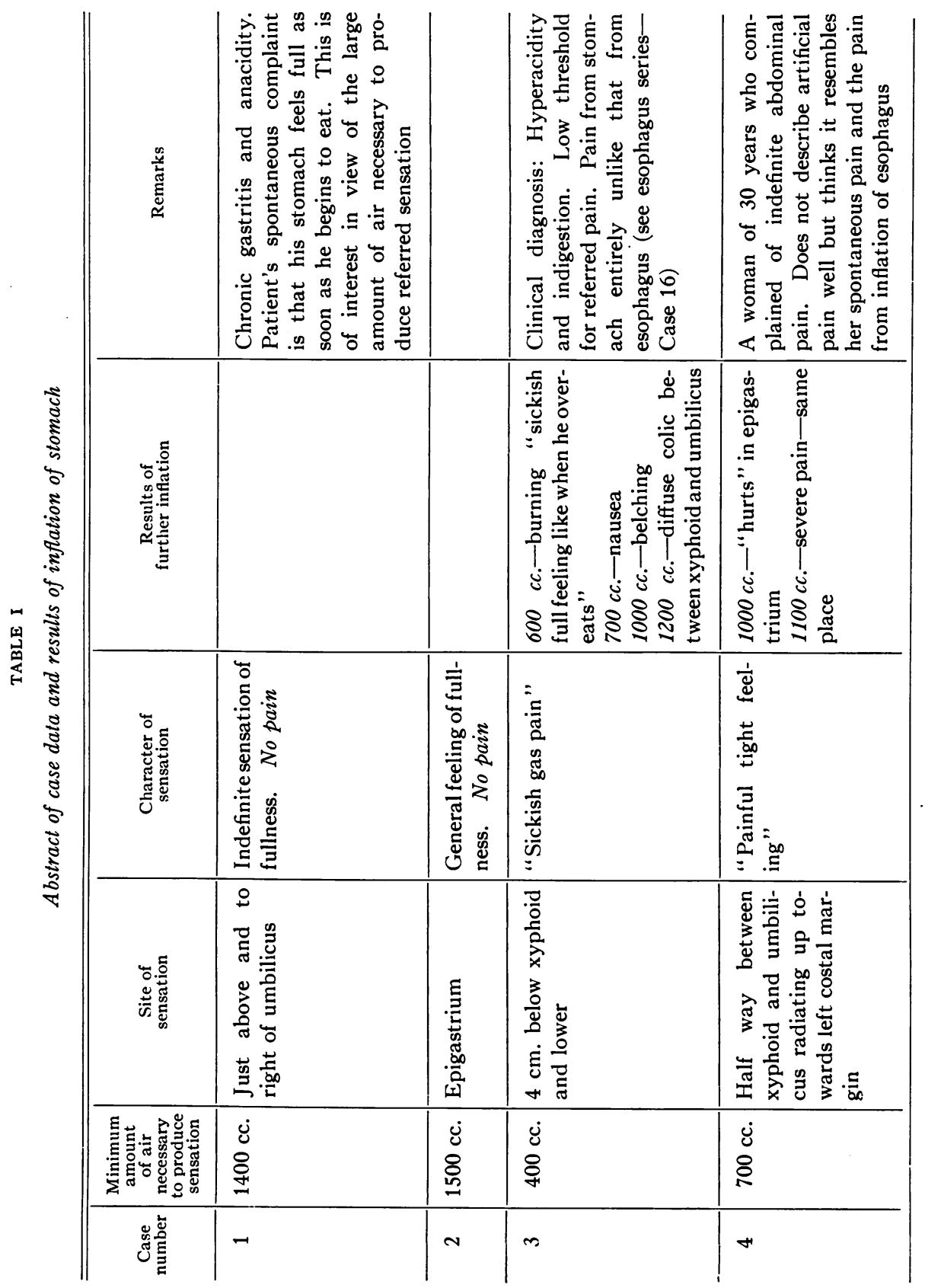




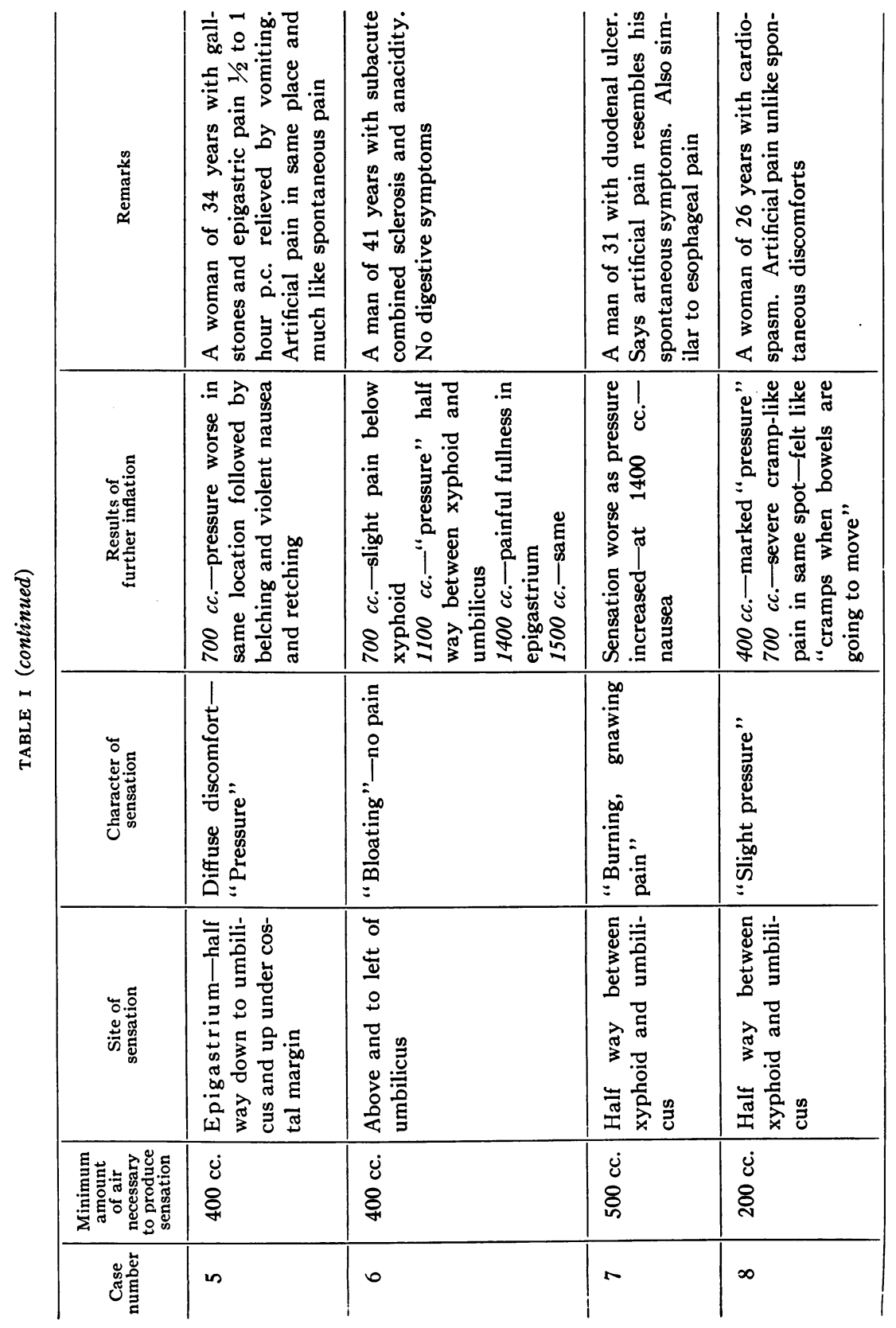


A. L. BLOOMFIEld AND W. S. POLlaND

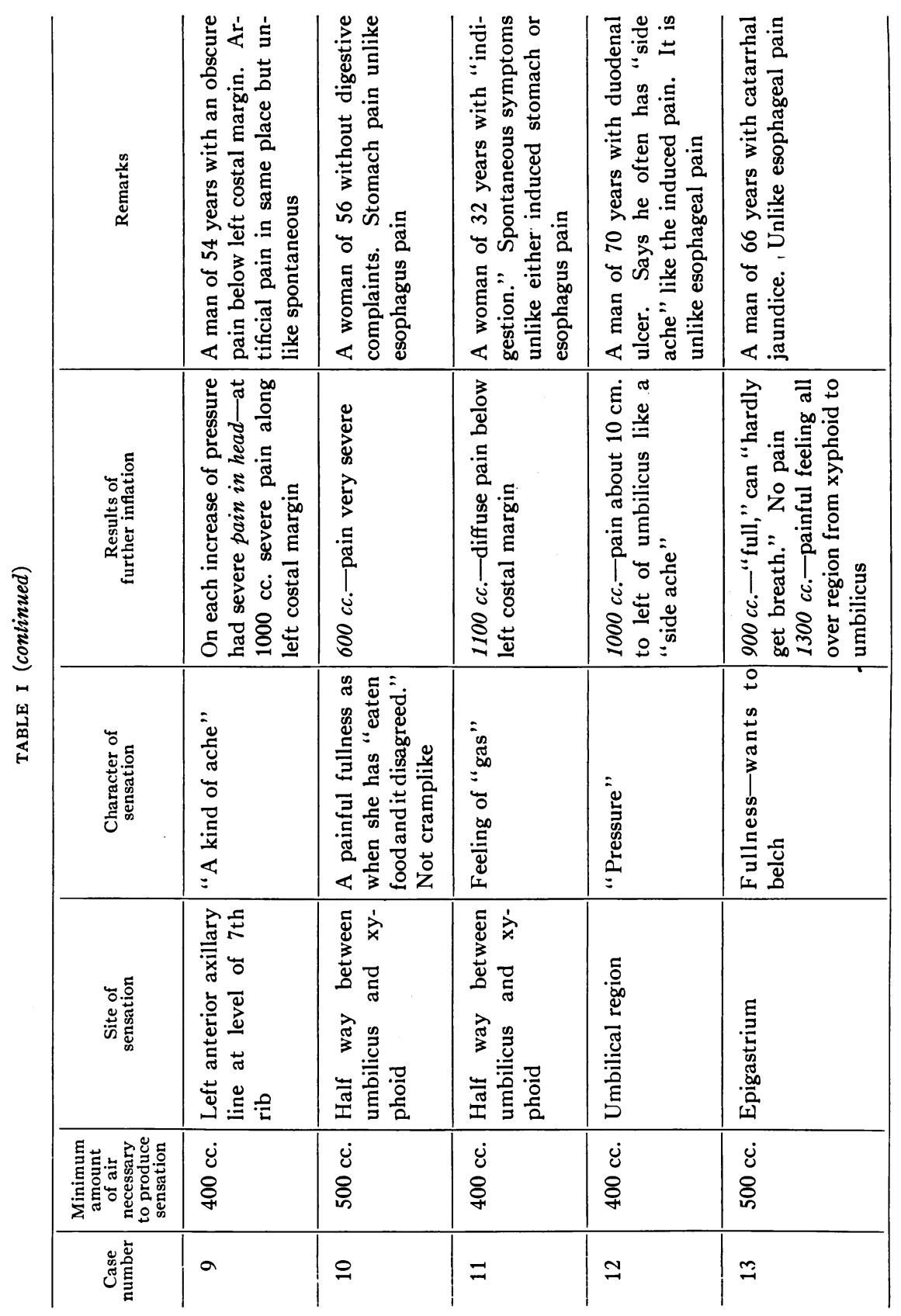




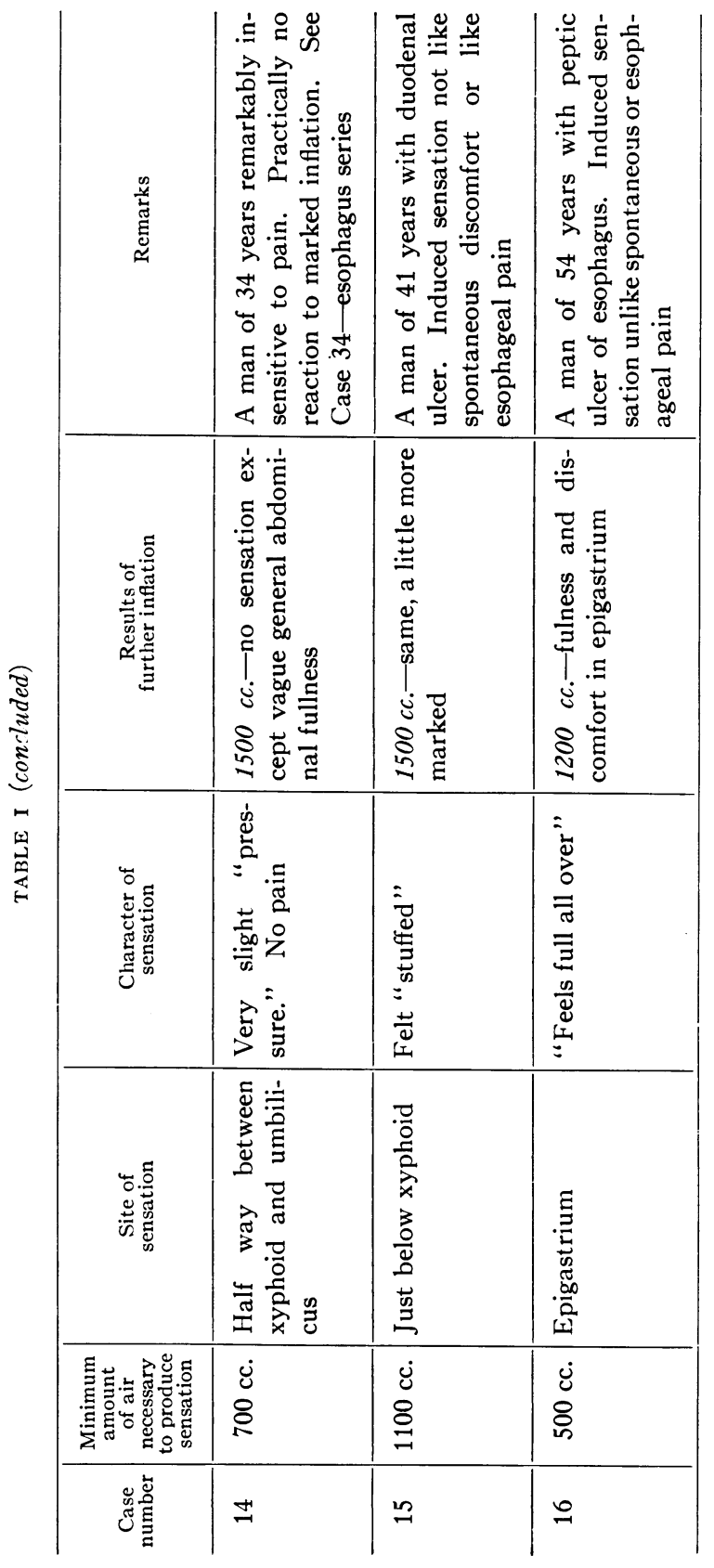


esophagus or duodenum. The subject usually placed his whole hand over the general area which was affected, but the sensation was usually described as deep and not on the surface. The dots in Fig. 2 show the centers of the areas indicated in the various cases; the total distribution of sensation corresponded roughly with the rectangular area. In no

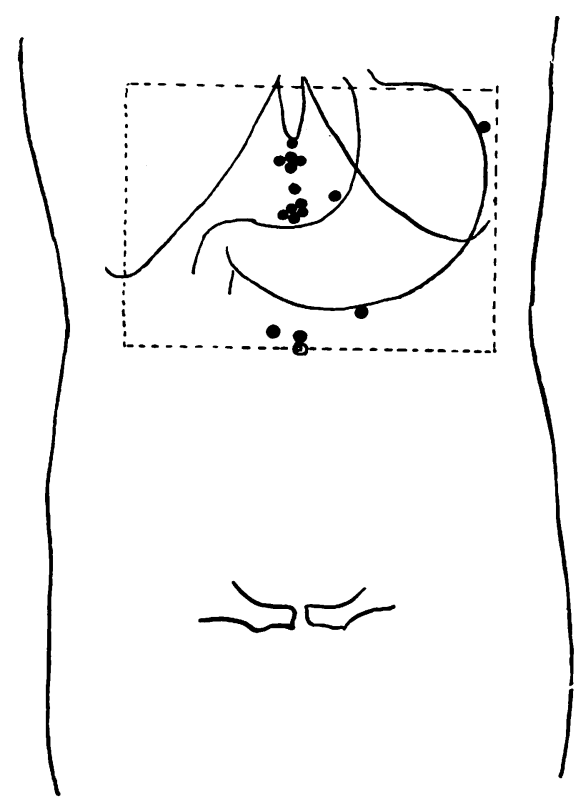

Fig. 2. Each Dot Indicates the Center of the Area of Referred Sensation.from Inflation of the Stomach in Sixteen Cases.

case did inflation of the stomach give pain much below the umbilicus or above the xyphoid with the exception of Case 9 who on each step in the inflation had severe pain in the temporal regions which was immediately relieved by releasing the pressure.

Relation of induced sensations to spontaneous discomforts and to esophageal and duodenal pain. In several cases (Cases $4,5,7,12$ ) the induced sensations were said by the patient definitely to resemble spontaneous discomforts. In Cases 4 and 7 the induced stomach sensation resembled that produced by inflation of esophagus. In other instances (see below) there was a resemblance between esophageal and duodenal pain. The point of interest and of clinical importance is the difficulty of identifying the site of the stimulus from the location of the referred sensation. 
PAIN: STOMACH, DUODENUM AND COLON
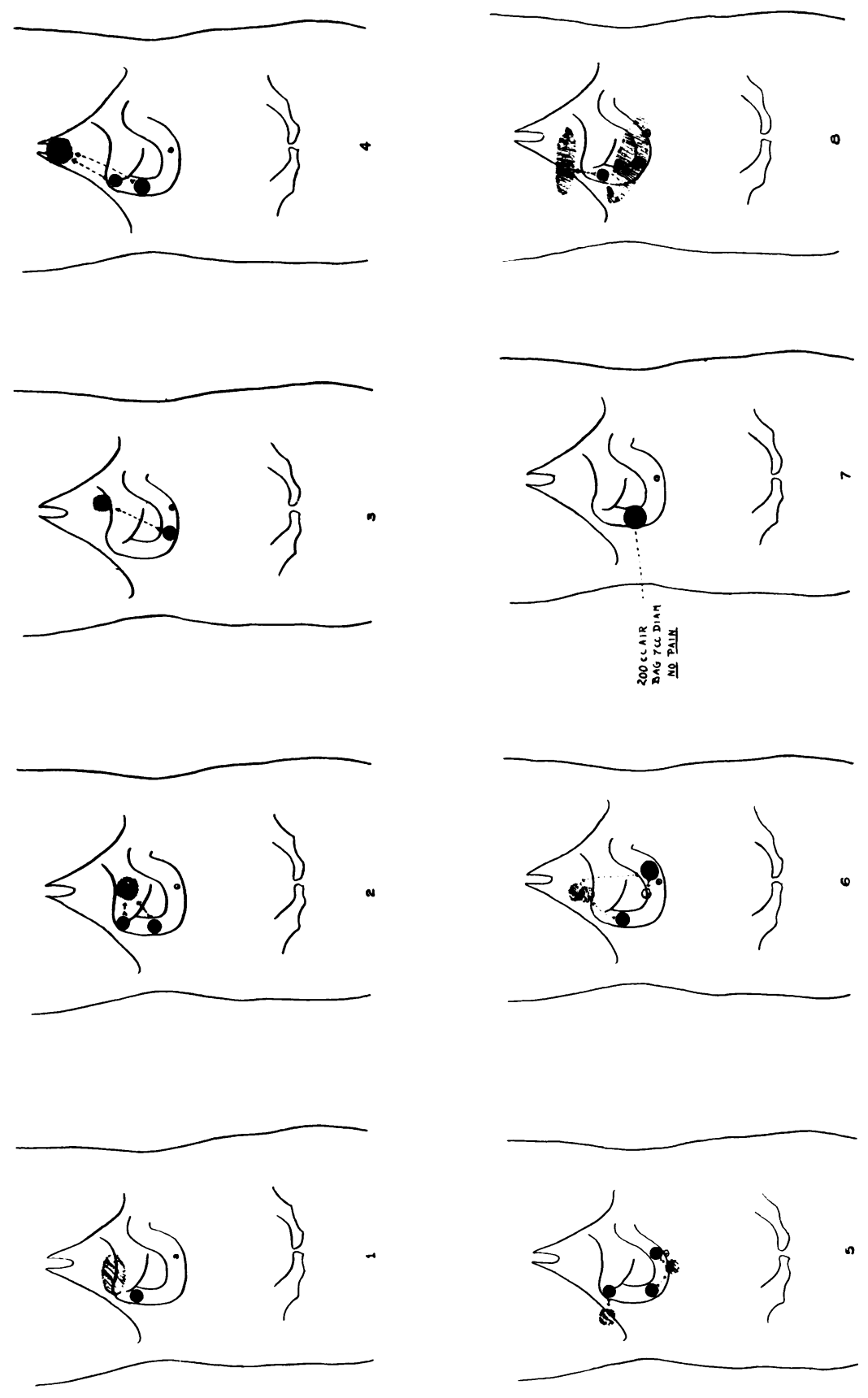
A. L. BLOOMFIELD AND W. S. POLLAND

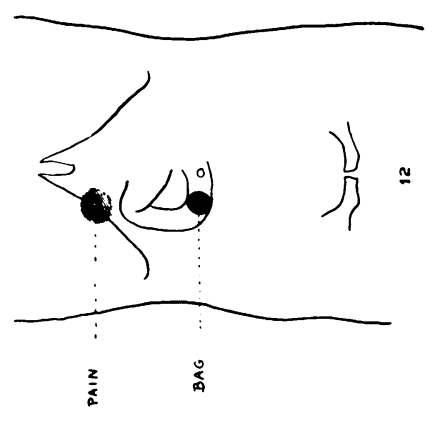

$\stackrel{1}{\Xi}$

.2

$\underset{\substack{a \\ \infty}}{\infty}$

$\stackrel{\Xi}{\longleftarrow}$

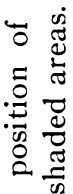

$\stackrel{\text { E }}{=}$

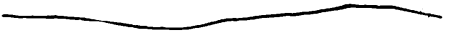

$\dot{\theta}$

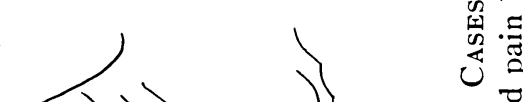

S.D $3=$

空总

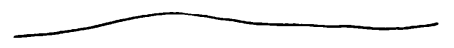

花

ह ज

$\sum_{0}$

覓:

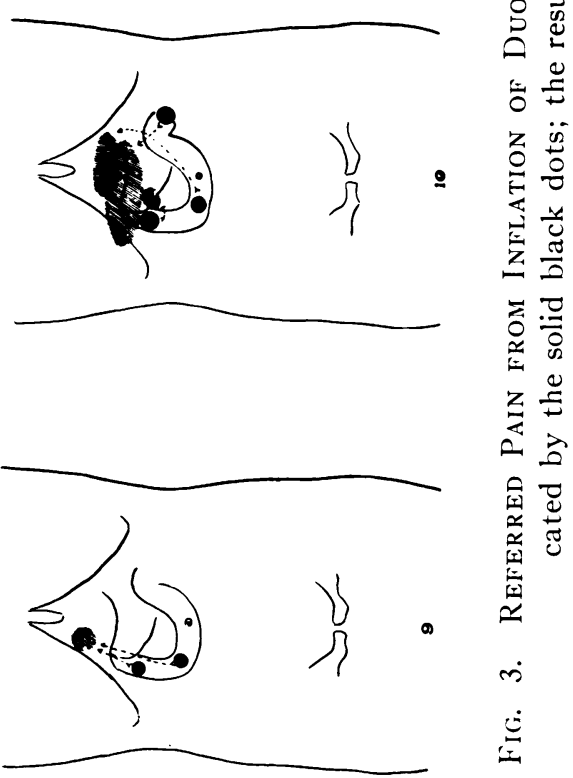


Mechanism of the referred sensations. The abdominal surface area implicated by the referred sensations corresponded to the 7 th, 8 th and 9 th dorsal segments. We interpreted the sensations as referred via the sympathetic. However, nausea and retching, and in Case 9 the pains in the head, seemed clearly to be reflexes through the vagus.

\section{DUODENUM}

Literature. Ivy, Vloedman and Keane (1) inflated the duodenum in three normal men with $50 \mathrm{cc}$. of air and produced nausea and chilliness. Strouse and Shamberg (2) carried out similar experiments in a larger series of people. In patients without abdominal disease they concluded that pain was localized at the position of the balloon whereas in cases of abdominal disease the results were variable or the patient's spontaneous pain might be reproduced. As will be seen below our experiments yielded somewhat different results.

Methods and material. A duodenal tube fitted with a balloon at its tip was used. The tube was passed in the usual manner and its position was verified under the fluoroscope. In a good many instances the balloon slipped back into the stomach as soon as inflation was begun so that only about one third of the experiments were successful. However, in twelve cases the procedure was carried out satisfactorily under fluoroscopic control. The exact position of the balloon, the amount of air necessary to produce sensation and the pressure in $\mathrm{mm}$. of mercury, the character of the pain and other symptoms and the location of induced sensations were recorded. The subjects included hospital patients with and without digestive symptoms.

Results. The main features of the observations are summarized in Table II and in Fig. 3.

The character of the referred sensations. The character of the referred sensations was similar to that obtained on inflation of the esophagus and stomach-deep seated more or less indescribable unpleasant feelings into which entered, in various cases, elements of pressure, fullness, burning, aching or colic. In a general way the induced discomforts resembled those complained of by patients with indigestion, peptic ulcer, gallbladder disease or other abdominal disorders. They presented no specific features. In several cases nausea and vomiting were induced. On relieving the inflation the referred sensation always disappeared instantaneously and there were no after effects. 
A. L. BLOOMFIELD AND W. S. POLLAND

463

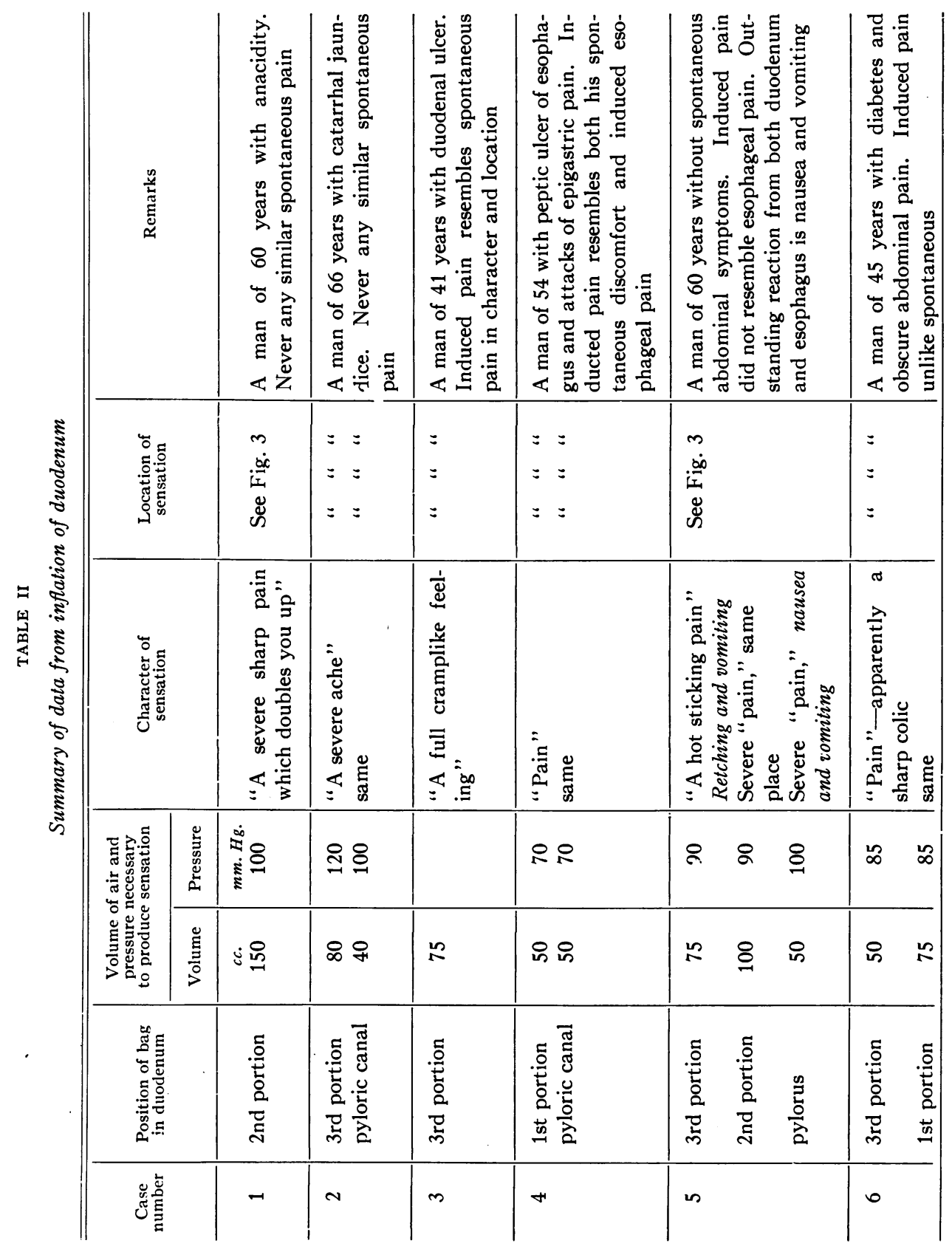


PAIN: STOMACH, DUODENUM AND COLON

\begin{tabular}{|c|c|c|c|c|c|c|}
\hline 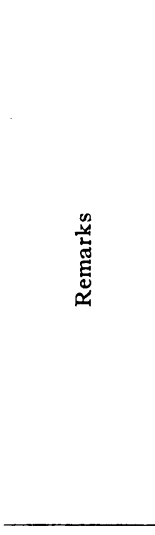 & 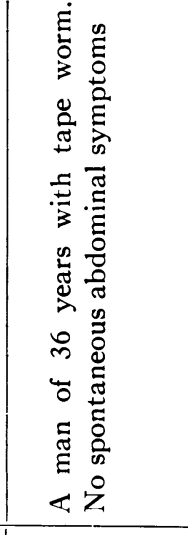 & 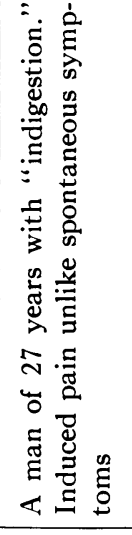 & 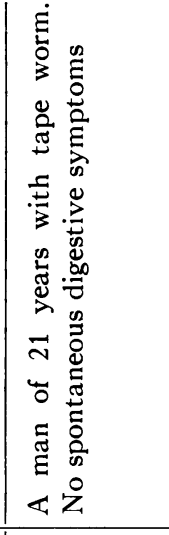 & 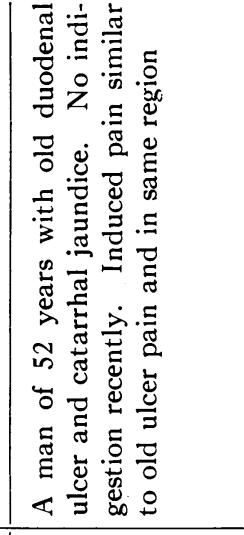 & 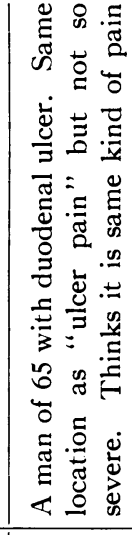 & 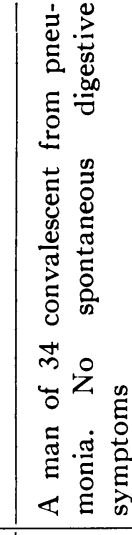 \\
\hline 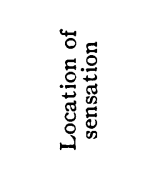 & 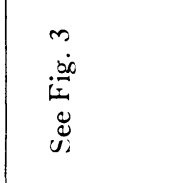 & $\begin{array}{l}= \\
=\end{array}$ & $=$ & $\begin{array}{l}: \\
: \\
:\end{array}$ & $\begin{array}{l}= \\
= \\
=\end{array}$ & $=$ \\
\hline 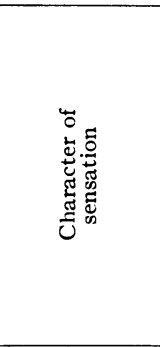 & 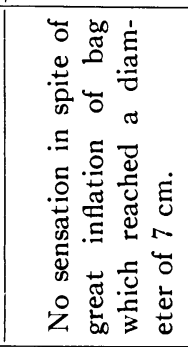 & 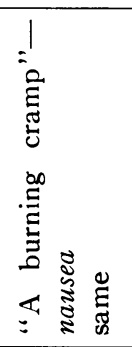 & 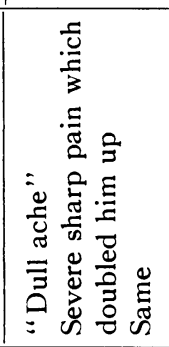 & 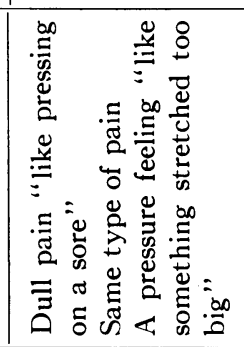 & 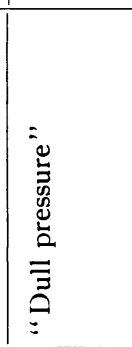 & 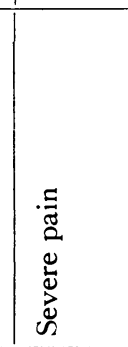 \\
\hline 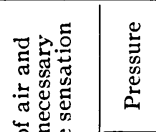 & 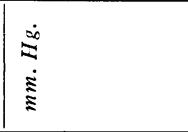 & 88 & 888 & $\infty \quad \infty \&$ & 8 & \\
\hline 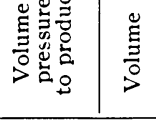 & ¿ఃర్ & in in & 요 & 朩 & $\stackrel{8}{8}$ & $\cong$ \\
\hline 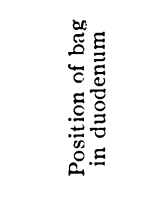 & 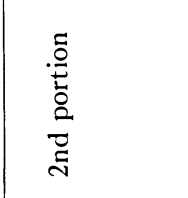 & 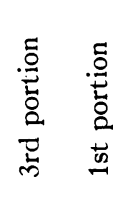 & 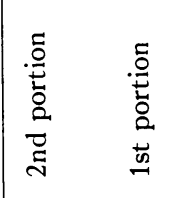 & 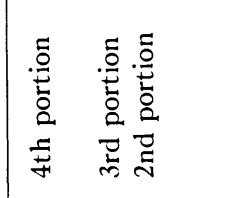 & 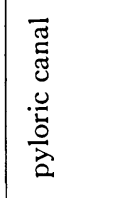 & 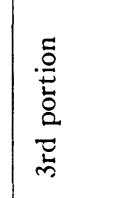 \\
\hline 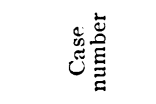 & r & $\infty$ & o & $\cong$ & $=$ & $\simeq$ \\
\hline
\end{tabular}


The location of the referred sensations. Fig. 3 shows the location of the referred sensations in relation to the position of the balloon in each case and Fig. 4 shows the center of pain in all the cases and the

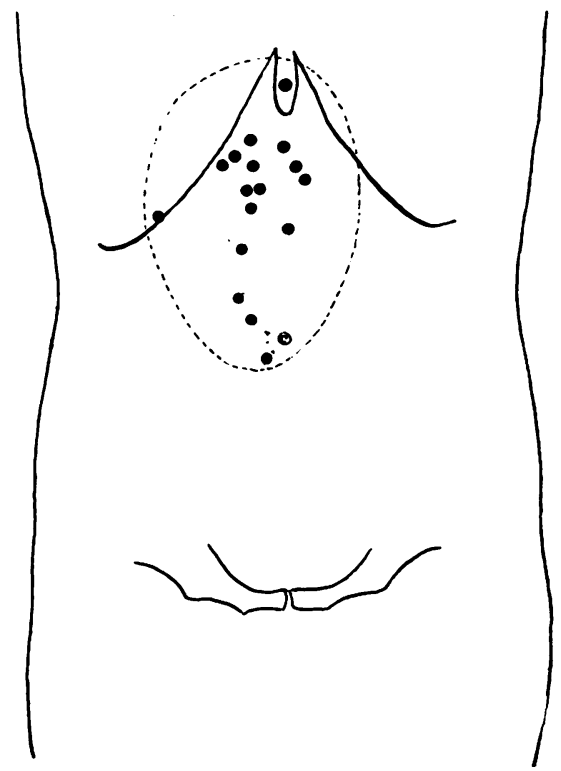

Fig. 4. Dotted Circle Indicates Total Area Implicated by Referred Pain from the Duodenum. Each dot indicates the site of pain from a single inflation.

total area which was implicated. It is seen that inflation of the duodenum may give pain from the xyphoid to the umbilicus although the right upper quadrant was most frequently referred to in these tests. We were unable to confirm Strouse and Shamberg's observation that in normals the pain was referred to the site of the balloon in contrast to other forms of reference in patients with intraabdominal disease; indeed in our cases there was no correlation of any sort. For the most part the referred pain was sharply localized (see diagrams) in contrast to the widely diffused sensations from the stomach. However the stomach and duodenal areas overlapped (see Fig. 7).

The degree of inflation necessary to produce pain. Table II shows that pain appeared in different cases with variable degrees of inflationfrom $40 \mathrm{cc}$. to $200 \mathrm{cc}$. of air. The pressure in the bag also varied con- 
siderably. Case 7 had no sensation even after the introduction of 200 cc. of air. It was impossible to correlate these variations with any clinical features such as presence or absence of disease of the duodenum, certainly the three cases of duodenal ulcer were not specially sensitive to inflation.

The relation of induced to spontaneous pain and of gastric esophageal and duodenal pain. Table III shows in summary these relations. In several cases inflation of duodenum reproduced the patient's spontaneous symptoms; in some instances these also seemed identical with induced pain from the esophagus. Obviously one should not go too far in drawing conclusions from statements of patients as to subjective sensations, but a point of great clinical importance is brought out insofar as one clearly must be very cautious in diagnosing the site of origin of a pain from its situation alone.

\section{COLON}

Great difficulties were encountered in introducing the balloon (see Fig. 1) into the large bowel and our observations are confined to inflations of the left colon and sigmoid. In order to prevent coiling of the tube in the rectum, which otherwise invariably occurred it was necessary to introduce the tube into the sigmoid through a proctoscope and then to attempt to pass it further. Successful observations, with the position of the bag checked by fluoroscopy, were obtained in nine patients with miscellaneous disorders, and except for Case 8 without bowel disease. We had found no reference in the literature to similar experiments on the intact bowel. Since this paper was completed we have learned that Chester M. Jones, of Boston, has presented a communication to the Cosmopolitan Club at their meeting on February 27,1930 , dealing with the problem of referred pain from the bowel as the result of inflation by means of balloons. From personal communication with Dr. Jones it appears that he has obtained results essentially similar to ours. It should also be pointed out that his present studies are the outgrowth of similar work on the esophagus which he reported several years ago at the meeting of the American Society for Clinical Investigation (5). Our work is therefore to be regarded as consequent and not antecedent to his.

Results. The results are summarized in Table IV and Figs. 5 and 6. 
A. L. BLOOMFIELD AND W. S. POLlAND

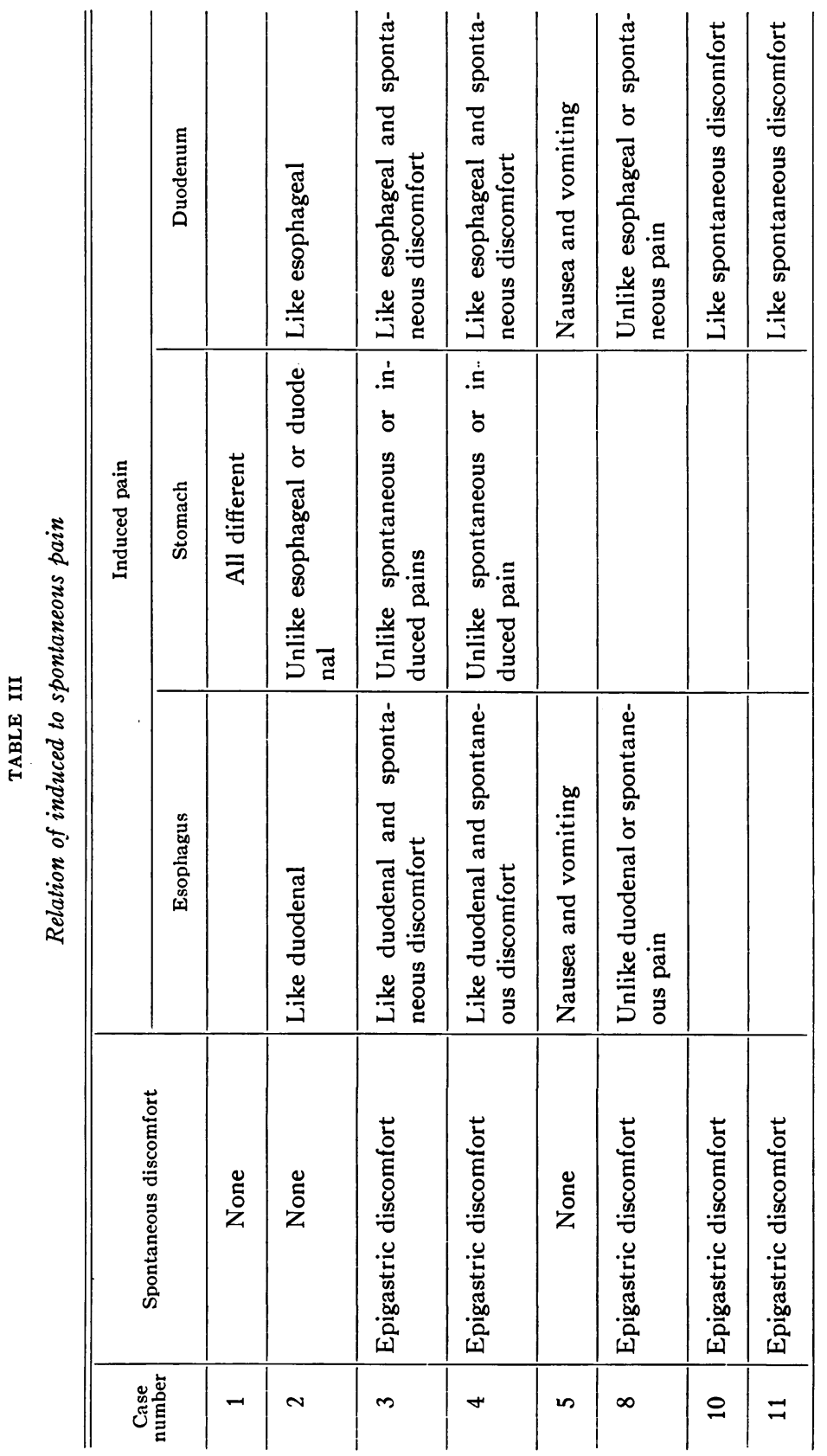



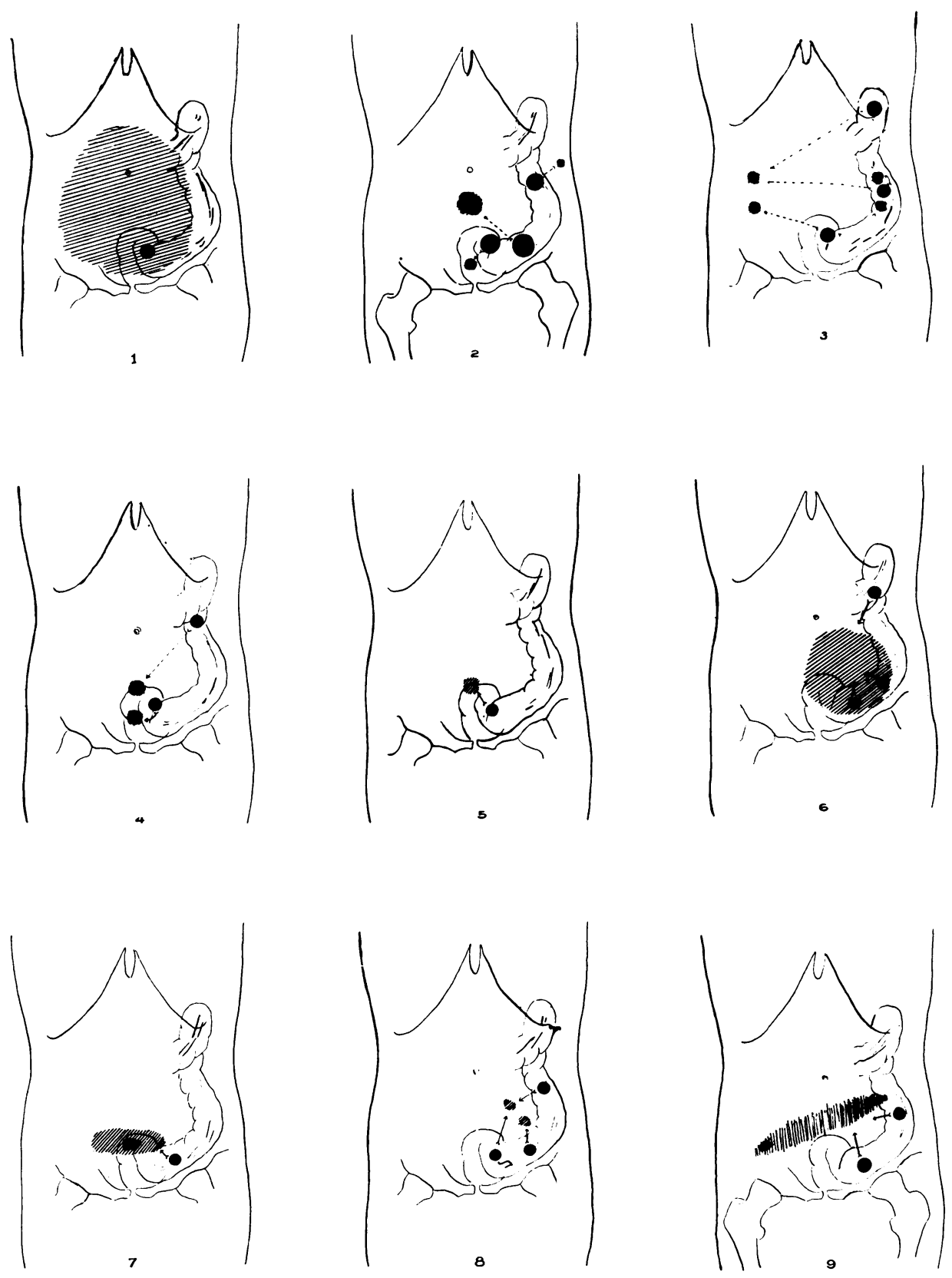

Fig. 5. Referred Pain from Inflation of Colon and Sigmoid in Nine Cases. The solid black dots show the position of the bag; arrows point to shaded areas which indicate the resulting areas of referred pain. 


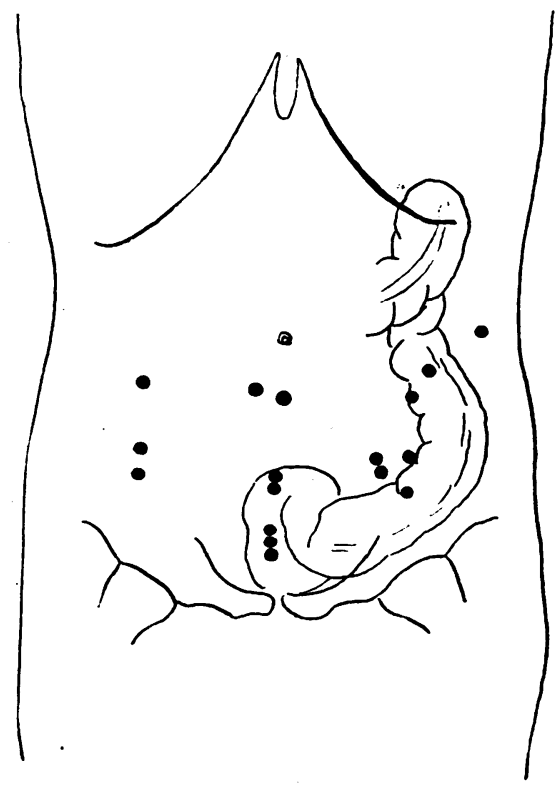

Fig. 6. Referred Pain from Colon. Each dot indicates the center of referred pain from a single inflation.

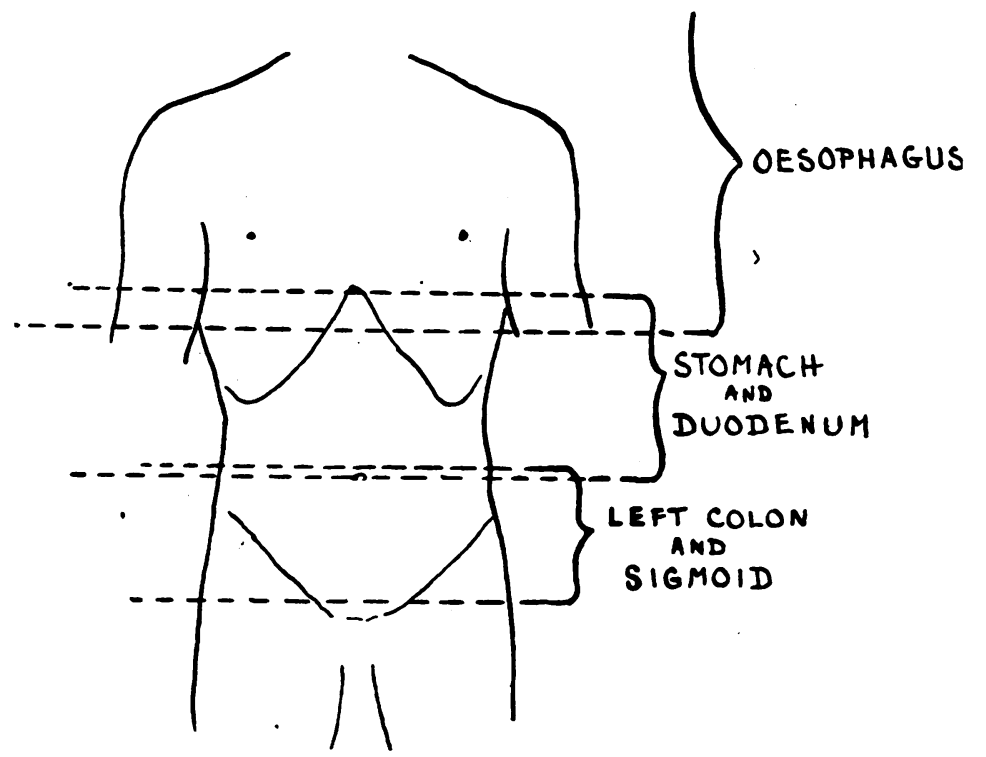

Fig. 7. Areas of Referred Pain Demonstrated by Inflation of Bal, LOONS IN THE Gastro-INTESTINAL TRaCt. 
PAIN: STOMACH, DUODENUM AND COLON

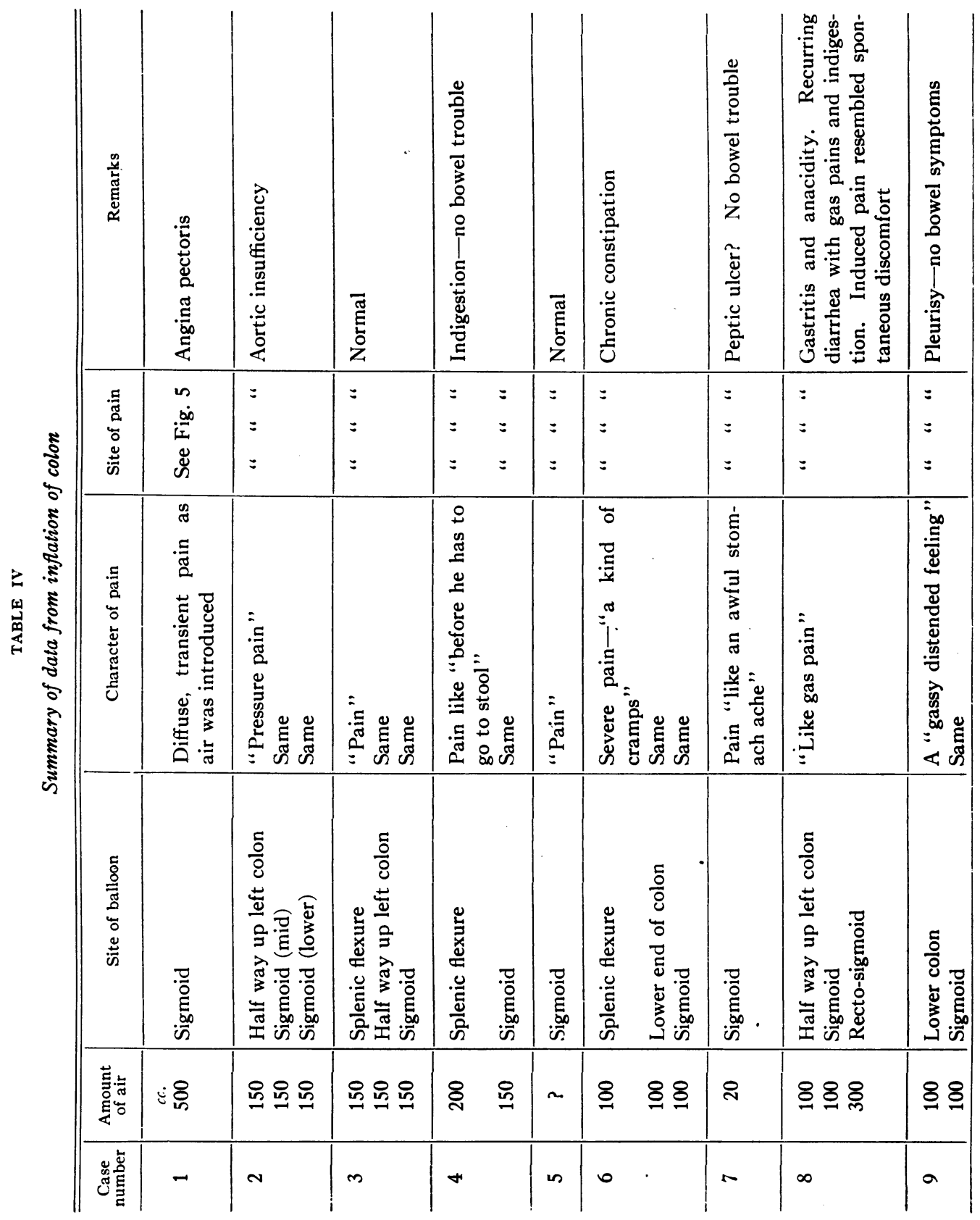


Referred sensations of the same general sort as those originating in the stomach or duodenum were obtained-more or less indescribable deep discomforts involving elements of fullness, pressure or colic and obviously related to sensations normally experienced in connection with movement of the bowel. As a rule pain appeared with about 100 to $200 \mathrm{cc}$. of air but in Case 7, $20 \mathrm{cc}$. sufficed and in Case 1, $500 \mathrm{cc}$. were necessary. We were unable to correlate these variations with any other features of the case. In some instances the pain was sharply localized as regards surface distribution as in Case 5 ; in others there was a wide indefinite area as in Cases 1 and 6 . In Fig. 6 each dot indicates the center of the area of referred sensation from a single inflation. It is seen that the whole area from umbilicus to pubis is implicated and that there was no definite relation between the site of the stimulus and the site of referred pain. Of special interest, for example, was Case 9 who with the bag in the descending colon felt pain in the right lower quadrant. In some cases the bag could be moved quite a distance without altering the position of the pain (Case 3). It is evident how uncertain it would be clinically to draw inferences as to the location of a lesion from the site of pain alone. As soon as the bag was drawn from the sigmoid into the upper rectum and inflated there a new type of sensation resulted, namely a pain low in the back similar to that experienced when the bowels are about to move.

\section{SUMMARY AND DISCUSSION}

These experiments show in brief that by inflating various parts of the gastro-intestinal tract with balloons referred sensations may be produced which fall under the general heading of pain. More in detail, these sensations may be described as deep seated fundamental more or less indescribable forms of discomfort into which enter elements classed by the subject as pressure, fullness, distension, tightness, cramps or burning. In many cases the subject recognizes the induced sensation as similar to spontaneous discomforts encountered in his past experience and likens them to the sensations of overeating, of indigestion, of desiring to go to stool, etc. For the most part the induced sensations seemed to be referred to segmental areas via the sympathetic, although in some cases nausea, vomiting and remote pain as in the head or face probably represented vagal reflexes. 
The main object of our studies was to throw light on clinical problems particularly with reference to the relation of site of pain to its point of origin, and it was brought out almost consistently that the superficial distribution of the referred sensations was remote from the site of the stimulus. One may mention, for example, pain in the suprasternal notch from inflation of the lower end of the esophagus, pain in the gallbladder region from inflation of the 3rd portion of the duodenum and pain in the lower mid-abdomen from inflation of the splenic flexure. While the total areas of referred sensation from esophagus, duodenum and colon are different, they overlap to some extent (see Fig. 7) so that at times it may be difficult to tell, for example, whether pain originates in the esophagus or in the upper abdominal viscera.

These facts seem to sustain the thesis laid down in the preceding paper (3) that symptoms of this sort occurring in patients do not by themselves enable one to make a diagnosis of the underlying disorder. This concept, even if not generally accepted at present, is not a new one and was championed by Sir James Mackenzie: "Attempts are continually being made to classify affections of the stomach, and the lack of agreement in these classifications is merely due to the fact that attempts are made to differentiate what can not be differentiated. This will be realized when the nature of stomach symptoms is considered. Apart from some characteristic vomits (blood, mucus), and certain changes indicated in the position of the organ (and these refer only to a minute proportion of the cases), all the symptoms are of a reflex nature, pain, cutaneous and muscular hyperalgesia, muscular contraction, vomiting and air suction. As any adequate stimulus may suffice to produce these symptoms, and as this adequate stimulus may arise from the most various causes, trivial or severe, it follows that there is a great similarity in the symptoms in diseases of the most varied kinds" (4). If all this be true it would seem to be sounder practice to admit the limitations of "digestive symptoms" in diagnosis and to realize that unless more conclusive evidence can be obtained by $\mathrm{x}$-ray study or in other ways it is unwise to set up criteria which actual experience shows to be unsound. 


\section{BIBLIOGRAPHY}

1. Ivy, A. C., Vloedman, D. A., and Keane, J., Am. J. Physiol., 1925, 1xxii, 99. The Small Intestine in Hunger.

2. Strouse, S. and Shamberg, A. H., Trans. Assoc. Am. Phy., 1925, xl, 296. Air Inflation of the Duodenum in Pathological Conditions of the Duodenum and Gall-Bladder.

3. Polland, W. S. and Bloomfield, A. L., J. Clin. Invest., 1931, x, 13. Experimental Referred Pain From the Gastro-Intestinal Tract: Part I. The Esophagus.

4. Mackenzie, James, Symptoms and Their Interpretation. London, Shaw, 1909, p. 128.

5. Jones, C. M. and Richardson, W., J. Clin. Invest., 1926, ii, 610. Observations on the Nature of "Heart Burn." 